\title{
A Mentorship and Networking Group for Women in Radiology
}

Lauren M. Ladd, Dana N. Bonaminio, Angela S. Gonda, Pauley T. Gasparis, W. Logan Bell, Vasantha D. Aaron, Darel E. Heitkamp

\section{THE PROBLEM: TOO FEW FEMALE ROLE MODELS IN RADIOLOGY}

Women are underrepresented in radiology [1]. A 2014 study found that the percentages of female practicing radiologists (23.5\%), academic radiology faculty (26.1\%), radiology residents (27.8\%), and radiology applicants (28.1\%) were all substantially below the percentage of women graduating from medical school in the United States (48.3\%) [2]. Additionally, of the twenty largest residency training programs in the US, radiology ranked ninth for overall size but only seventeenth for female representation [2].

As the medical field has become increasingly diverse, radiology has failed to keep pace. Over the last four decades, the percentage of female radiologists in the United States has held steady in the low to mid-20s [2,3,4,5]. Many studies have been conducted in recent years to better understand the forces behind the apparent gendering of certain medical specialties, a term which reflects the overwhelming predominance of women in some specialties such as pediatrics and obstetrics-gynecology and men in others such as radiology and orthopedic surgery $[6,7,8]$. Although these studies failed to reveal conclusive evidence as to the causes, they managed to uncover potential contributing factors, such as the presence of gender bias in certain specialties, cultural differences between the sexes, and the presence or lack of identifiable role models in different fields $[6,7,8,9]$. The forces that produce gender disparity in medical specialties are 
vitally important to understand and improve, as diversity is believed to be a key element to improving equal access to health care in the United States [2,10,11,12].

The presence of strong relatable role models is commonly identified as a crucial element in the specialty choices of medical students $[12,13,14,15]$. Studies in multiple medical specialties including radiology have shown that women, more so than their male counterparts,

were found to rate role models as highly valuable resources for the selection of career specialties $[12,13,14]$. Some authors have suggested that it is the lack of visible female role models in male gendered specialties that makes it difficult for female medical students to visualize themselves in those professions $[7,8]$. To this point, residents and educators at our institution felt that this was an actionable problem that could be improved with a locally organized mentorship program for women.

\section{WHAT WAS DONE: A MENTORSHIP AND NETWORKING GROUP FOR WOMEN}

In July 2013, resident organizers at the Indiana University Department of Radiology were approved to establish the Women in Radiology (WIR) Group, a voluntary department-sponsored organization aimed at creating a platform of support for female radiologists in our department and female students at our medical school. The WIR Group has several important primary goals: (1) to provide valuable mentorship and networking resources for women associated with the department of radiology, including medical students, residents, fellows, faculty, and alumni; (2) to enable the development of skills essential for success in medicine today, including leadership, research, business, negotiation, networking, and work-life balance; and (3) to work toward improving the gender gap within radiology by providing successful female role models to mentor and educate medical students regarding potential careers in radiology. 
Career planning and advancement are essential elements of the group's focus, relying on the mentorship model of learning. The group also strives to provide an important venue for innovation and exchange of ideas among female radiologists in the department and community. Time is spent discussing topics specific to working mothers such as how to approach colleagues regarding maternity leave, advice on child care, and work-life balance. Other important topics such as philanthropy also constitute part of the regular programming.

\section{Structure and Support}

Leadership positions within the group are determined annually and filled by trainees, with appointed positions of president, vice president, and secretary-treasurer. General meetings are held every other month with agendas set by the WIR trainee and faculty leadership. Meeting topics vary but often include guest speakers, leadership and research updates, book and journal club discussions, updates regarding fellowship and job opportunities, and mentor-mentee roundtables.

The group has strong support from the residency director and department chairman and is recognized by the department with an annual operating budget of $\$ 2500$. This is used primarily to support mentorship events, visiting speakers, and medical student outreach. There are two primary faculty sponsors who attend meetings and provide guidance for group affairs. Additional female faculty, alumni, and local community radiologists attend meetings, offer input during discussions, and serve as trainee mentors.

\section{Mentorship Model}

The WIR organization utilizes a paired mentorship model which matches a trainee with a practicing radiologist in the area. In an effort to optimize compatibility, mentorship pairing is initially made with information provided by surveys taken by both the staff radiologists and the 
trainees. These brief surveys, which elicit preferences regarding personal and professional interests, are used to match the goals of the students, residents, and fellows with the interests and expertise of the practicing radiologists. Using this model, the WIR mentoring program is able to successfully address the vast range of needs demonstrated by trainees of different backgrounds and experience levels. For example, in our experience, lower level residents tend to be most interested in advice regarding fellowship specialties, opportunities for leadership and research, and preparation for the American Board of Radiology qualifying examination. Upper level residents, having taken their qualifying exams and secured their fellowships, tend to focus on issues related to job searching and honing the radiology skills needed for smooth transitions to independent practice.

Mentorship events are scheduled during regular WIR meetings and at other times convenient for members, such as working lunch meetings at local restaurants. Female radiologists in private practice also serve as mentors, enabling the discussion of important issues related to private practice group structure, efficiency benchmarks, and contract negotiation. Because the organization recognizes the crucial role that role models play in physician development, the mentorship model serves as the centerpiece of the WIR organization, around which the remainder of the programming is planned.

\section{Meeting Topics}

\section{Guest Speakers}

Local women are invited to discuss selected topics of interest to the group. Speakers are recruited from a wide spectrum of careers, including radiology, clinical medicine, and even the business community, in an effort to share their individual perspectives for success. Topics 
discussed by outside speakers to date include the gender pay gap and job negotiation strategies for women in radiology.

\section{Journal Club}

The WIR organization values interactive learning through group discussion of books and journal articles. Current literature regarding professionalism, women in the work force, ethics, and leadership are selected by faculty sponsors or WIR leaders for members to read and discuss at meetings. The journal club enables improved awareness and understanding of these important issues.

\section{Fellowship and Job Updates}

Substantial meeting time is also devoted to discussing the important issues regarding fellowship selection and job searching. Upper level residents and fellows share experiences related to the fellowship application process and individual program strengths. Alumni and community radiologists discuss the practice models and current hiring trends of their respective groups. Additionally, job opportunities are shared with members to introduce potential job leads and provide an evolving overview of the local and regional job market.

\section{Medical Student Outreach}

Medical student outreach is an important activity of the WIR Group. The group has an appointed resident member who serves as medical student liaison, a position designed to actively engage and communicate with female students in all four years of medical school. Additionally, a female medical student from the school's radiology student interest group is appointed as WIR liaison to help educate and promote medical student attendance at WIR events.

Educating female medical students about radiology requires both dispelling the common misconceptions and stereotypes as well as outlining the numerous opportunities for patient care, 
collaboration, and career satisfaction. Medical student outreach is incorporated into many facets of WIR programming, most notably through the dedicated panel discussions for female medical students featuring current radiology residents, fellows, and faculty. Other opportunities for student engagement include the WIR guest speaker events, which are heavily advertised on student email listservs, and dedicated social events for medical students and radiology residents that are planned throughout the year.

\section{OUTCOMES}

A ten-question web-based survey (SurveyMonkey, Palo Alto, CA) of the WIR trainee membership was performed after two and a half years of group operation. Questions were designed to elicit members’ opinions of how well the group provides effective mentorship, camaraderie, and resources related to research, leadership, networking, career planning, worklife balance, fellowship planning, and job opportunities.

The results of the survey showed that $90 \%$ of the trainee members agreed or strongly agreed that the WIR group provides a much-needed networking platform for female radiologists in our area. Seventy percent of the women agreed or strongly agreed that the group has improved camaraderie among women radiologists. Sixty percent of respondents felt that the group has been essential to raising awareness of important issues specific to women within radiology. Free-form comments regarding the effectiveness of the group’s mentorship program yielded the following responses:

My mentor and I have met outside of the events of WIR and it was great getting to hear unsolicited advice on radiology and life. My mentor is awesome. It was a great idea pairing us with mentors in this "mini match".

I think it has reinforced a bond between myself and my mentor. It gives me an outlet to turn to regarding issues I face as a woman in medicine. 
As a first year, it has been great to connect with female staff outside of work and build relationships with these awesome women. It's motivational to see what my future could be like and how women make it work with balancing work and life with a family.

In addition to providing service and leadership positions within the administration of the WIR Group itself, the organization has devoted time to identifying important leadership opportunities elsewhere in radiology and medicine. Members of the group have represented the department at numerous regional and national conferences, including annual meetings of the Indiana Radiological Society, the American College of Radiology, the Association of University Radiologists, the American Roentgen Ray Society, and the Radiological Society of North America. The WIR Group’s first president served in a national leadership position as the Resident Division Awards Chair of the American Medical Women’s Association.

There also appears to be a slight uptick in the number of female Indiana University medical students pursuing careers in diagnostic radiology since the start of the WIR Group. In the three years that have passed since the inception of the group, there have been thirteen female medical students who have secured diagnostic radiology residency positions through the match. In the three years prior to the WIR Group, there were only ten female students from Indiana University who entered radiology. Although the overall numbers are somewhat low, these preliminary data represent a 30\% increase in female applicants after the start of the group.

\section{CONCLUSION}

The WIR Group at Indiana University is a successful networking and mentoring group that provides important resources for female medical students, residents, fellows, and practicing radiologists. We believe that its strong mentorship program and active medical student outreach 
are vital to the group's objective of eliminating the gender gap within radiology. Comments from trainee members reflect the vital role that the group is providing in developing female radiologists in central Indiana. We believe the model could be easily reproduced to create similar networking and support groups for women at other institutions.

\section{References}

1. Baker SR, Barry M, Chaudhry H, Hubbi B. Women as radiologists: are there barriers to entry and advancement? J Am Coll Radiol 2006;3:131-4.

2. Chapman CH, Hwang WT, Both S, Thomas CR, Deville C. Current Status of Diversity by Race, Hispanic Ethnicity, and Sex in Diagnostic Radiology. Radiology, 2014;270:232-40.

3. Fielding JR, Major NM, Mullan BF, et al. Choosing a specialty in medicine: female medical students and radiology. AJR Am J Roentgenol 2007;188:897-900.

4. Deitch CH, Sunshine JH, Chan WC, Shaffer KA. Women in the radiology profession: data from a 1995 national survey. AJR Am J Roentgenol 1998;170:263-70.

5. Evens RG. Women in radiology. Radiology 1987;164:282-3.

6. Alers M, van Leerdam L, Dielissen P, Lagro-Janssen A. Gendered specialties during medical education: a literature review. Perspect Med Educ 2014;3:163-78. 
7. Hill EJR, Giles JA. Career decisions and gender: the illusion of choice? Perspect Med Educ 2014;3:151-4.

8. Hill E, Vaughan S. The only girl in the room: how paradigmatic trajectories deter female students from surgical careers. Med Educ 2013;47:547-56.

9. Potterton VK, Ruan S, Sunshine JH, Applegate K, Cypel Y, Forman HP. Why don't female medical students choose diagnostic radiology? A review of the current literature. J Am Coll Radiol 2004;1:583-90.

10. Institute of Medicine. In the Nation's Compelling Interest: Ensuring Diversity in the Health Care Workforce. Washington, DC: National Academy of Sciences, 2004.

11. Lightfoote JB, Deville C, Ma LD, Winkfield KM, Macura KJ. Diversity, inclusion, and representation: it is time to act. J Am Coll Radiol 2016;13:1421-5.

12. Roubidoux MA, Packer MM, Applegate KE, Aben G. Female medical students’ interest in radiology careers. J Am Coll Radiol 2009;6:246-53.

13. Neumayer L, Kaiser S, Anderson K, et al. Perceptions of women medical students and their influence on career choice. Am J Surg 2002;183:146-50.

14. McMurray JE, Schwartz MD, Genero NP, Linzer M. The attractiveness of internal medicine: a qualitative analysis of the experiences of female and male medical students. Ann Intern Med 1993;119:812-8.

15. Maudsley RF. Role models and the learning environment: essential elements in effective medical education. Acad Radiol 2001,76:432-4. 